\title{
Impact of Increased Amino Acid Intake on Very Low Birth Weight Infants Siddharthan Sivamurthy, M.D. ${ }^{1}$, Carolyn R. Ahlers-Schmidt, Ph.D. ${ }^{1}$, Katherine S. Williams, M.Ed. ${ }^{1}$, Jared Shaw ${ }^{2}$, Paula Delmore, M.S.N. ${ }^{2}$, Barry T. Bloom, M.D. ${ }^{1,2}$ \\ ${ }^{1}$ University of Kansas School of Medicine-Wichita, Department of Pediatrics \\ ${ }^{2}$ Wesley Medical Center, Department of Neonatology
}

\begin{abstract}
Background. A consensus has not been reached on whether higher doses of parenteral amino acids improve growth in preterm infants without causing adverse side effects. The objective of this study was to evaluate the impact of a more rapid increase in amino acids dosing in very low birth weight (VLBW) infants during their first few days of life.
\end{abstract}

Methods. The study design was a 1:1 ratio case matched retrospective analysis of data from two distinct periods when the hyperalimentation practice differed. During phase I, a five-day incremental dose of amino acids was utilized. In phase II, a two-step dose increase of amino acids was practiced. Duration of total parenteral nutrition (TPN), weight at 28 days, hepatic and renal function tests, and rates of complications were compared. This study was approved by two local IRBs.

Results. The phase II protocol resulted in an increased dose of amino acid delivered by day 7 (16 $\mathrm{g} / \mathrm{k}$ vs $12.8 \mathrm{~g} / \mathrm{k}, \mathrm{p}<0.001)$. This increased dose of amino acids resulted in a shorter duration of TPN usage (16 days vs 18 days, $\mathrm{p}=0.001)$. The increased dosage did not have a detrimental effect on hepatic or renal function. It also did not increase the incidence of feed intolerance or bowel perforation. However, an increase in amino acid dosing did not increase absolute weight gain $(15 \mathrm{~g} / \mathrm{k} /$ day vs $13 \mathrm{~g} / \mathrm{k} /$ day, $\mathrm{p}=0.282)$.

Conclusions. No unfavorable outcomes were demonstrated with this increased amino acid regimen. VLBW infants may be able to tolerate even higher doses in the first month after birth.

KJM 2011; 4(2):31-36.

\section{Introduction}

Considerable research in the area of nutrition for preterm infants has resulted in a sea change in clinical practice over the last several years. Infants born prematurely miss out on an important period of in-utero protein accretion. Multiple etiologies for growth failure in the Neonatal Intensive Care Unit (NICU) have been recognized and one of them is the lack of early administration of intravenous amino acids. ${ }^{1}$ Evidence suggested this influences growth and long term developmental outcomes. ${ }^{2,3}$

Most infants between 24 and 29 weeks gestation do not achieve the median birth weight of the reference fetus of the same gestation at the time of discharge. ${ }^{4}$ For these preterm infants to match an intrauterine rate of growth, it has been postulated that amino acid infusion rates as high as $4 \mathrm{~g} / \mathrm{k} /$ day would be required. ${ }^{5}$ Amino acid supplementation at $3 \mathrm{~g} / \mathrm{k} / \mathrm{day}$, soon after birth, results in a significant decrease in the number of infants falling below the $10^{\text {th }}$ percentile for weight at 36 weeks corrected gestation and shortens time to full enteral feeds. ${ }^{6}$ This may be responsible for improved weight gain.

Early introduction of amino acids with an increase up to a maximum of 3.5 to 4 $\mathrm{g} / \mathrm{k} /$ day did not result in a higher incidence of adverse effects like hepatic or renal dysfunction. ${ }^{7,8}$ Despite this, fears remain about the ability of very low birth weight (VLBW) infants to cope with high doses of amino acids. 
Increased blood amino acid levels have been reported using $3.5 \mathrm{~g} / \mathrm{k} /$ day when compared to $2.5 \mathrm{~g} / \mathrm{k} /$ day, without the much desired improvement in weight gain. ${ }^{9}$ So, does an increased blood amino acid level imply toxicity? Amino acid infusions of 3 $\mathrm{g} / \mathrm{k} /$ day in neonates weighing less than 1300 grams resulted in blood profiles of amino acids that were equal to or less than those seen in $2^{\text {nd }}$ and $3^{\text {rd }}$ trimester fetuses sampled by cordocentesis. ${ }^{10}$ This is supported by an earlier observation that enteral intakes approximating 3.2 to $3.5 \mathrm{~g} / \mathrm{k} /$ day more closely mimicked intrauterine estimations for nitrogen retention. ${ }^{11}$ Thus, amino acids at these doses are likely to be tolerated physiologically.

Historically, amino acids were introduced cautiously by increasing the dose gradually over several days. An evidencebased change in practice was made to administer a higher dose of amino acid at an earlier time in the first week. This change presented an opportunity to compare these two distinct periods for weight gain and the incidence of adverse events like hepatic and renal dysfunction. We hypothesized that this newer practice had resulted in an increased administration of amino acids, better weight gain, and minimal or no adverse effects. This investigation sought to replicate the findings of previous smaller studies with a larger population size. ${ }^{7}$

\section{Methods}

The phase I practice was to introduce intravenous amino acids at $0.5 \mathrm{~g} / \mathrm{k} /$ day on day 1 and increase by $0.5 \mathrm{~g} / \mathrm{k} /$ day up to a maximum of $2.5 \mathrm{~g} / \mathrm{k} /$ day. The phase II practice was to start on day 0 with $2 \mathrm{~g} / \mathrm{k} /$ day and increase to $3 \mathrm{~g} / \mathrm{k} /$ day once the total intake reaches $100 \mathrm{ml} / \mathrm{k} /$ day. Beyond the first week, infants were advanced based upon individualized decision making to a maximum of $3.5 \mathrm{~g} / \mathrm{k} /$ day in their total parenteral nutrition (TPN).
There is an inherent high degree of variability in protein administration. Infants in phase II are started at $2 \mathrm{~g} / \mathrm{k} / \mathrm{d}$ and only increased to $3 \mathrm{~g} / \mathrm{k} / \mathrm{d}$ when the fluid intake is increased to $100 \mathrm{ml} / \mathrm{k} / \mathrm{d}$. This increase in fluids is dependent on the infant's cardiovascular and respiratory status, hence is variable. Consequently, the "desired protein intake at 7 days" is not a set amount but the most the individual infant is clinically able to tolerate.

The study aim was to compare the two groups retrospectively with a convenience sample. Infants between the gestational ages of 23 and 33 weeks with birth weights between $501 \mathrm{~g}$ and $1500 \mathrm{~g}$ were selected. Infants who were small for gestational age, had congenital anomalies, died, or were transferred acutely were excluded.

The two groups were case matched 1:1 based on same week of gestation at birth and within $50 \mathrm{~g}$ birth weight (see subject selection in Figure 1). The groups were compared for differences in weight gain, days of total parenteral nutrition (TPN) usage, and laboratory evidence of renal and hepatic dysfunction. Laboratory levels more than three times in excess of the upper reference range were considered clinically relevant. The incidence of complications like feed intolerance and bowel perforation were compared between the two groups. This study received approval from two local Institutional Review Boards.

Data analysis. Comparisons were made between the demographic characteristics of phase I and phase II subjects to establish similarity. Total protein doses at day 7 and day 28, duration of enteral feeding, total days of TPN, and weight gain at 28 days were compared between the two groups. The rates of adverse effects, namely hepatic and renal dysfunction, as well as feeding intolerance and bowel perforation also were compared. The Statistical Package for the Social Sciences (SPSS) 17.0 was used for 
Total no. of patients in database $=8293$

Exclusion

(Discharge before 12/1/2000 or after 12/31/2008,

Birth date between 12/1/2004 and 10/31/2005)

Remaining patients $=5236$

Further exclusions

BW $(<501 \mathrm{~g} \&>1500 \mathrm{~g}), \mathrm{GA}(<23 \mathrm{wk} \&>33 \mathrm{wk})$, SGA

Died / Transfer $<28$ days and Congenital anomalies

Final patient count $=573$

$$
\begin{gathered}
\text { Phase } \mathrm{I}=291 \quad \text { Phase } \mathrm{II}=282 \\
\text { Matched pairs }=181
\end{gathered}
$$

Figure 1. Characteristics of subject selection. Abbreviations:

BW - birth weight, GA - gestational age, SGA - small for gestational age.

data analysis. Categorical comparisons were made using the chi square test and continuous comparisons by the Wilcoxon signed rank test. A p value of less than 0.05 was used to indicate statistical significance.

\section{Results}

Table 1 shows the demographic characteristics of the study sample. There were no significant differences between the two phases of clinical practice in gestational age, birth weight, gender, multiple gestation, and ethnicity. The duration of intravenous nutrition was significantly less in phase II ( 16 days vs 18 days, $\mathrm{p}=0.001$; see Table 2 ). The dose of amino acids received in phase II was significantly higher in the first 7 days $(16 \mathrm{~g} / \mathrm{k}$ vs $12.8 \mathrm{~g} / \mathrm{k}, \mathrm{p}<0.001)$. However, when measured at 28 days, there was no significant difference.
As shown in Table 3, there was no significant increase in the incidence of feeding intolerance (20 vs $13, \mathrm{p}=0.201$ ) or bowel perforation ( 0 vs $2, \mathrm{p}=0.499)$ in phase II. An increase in BUN was noted on day 1 in phase II $(18 \mathrm{mg} / \mathrm{dl}$ vs $14 \mathrm{mg} / \mathrm{dl}, \mathrm{p}<$ 0.001; see Table 3). Clinically irrelevant but statistically significant increases were noted in the day $7 \mathrm{BUN}(19 \mathrm{mg} / \mathrm{dl}$ vs $18 \mathrm{mg} / \mathrm{dl}, \mathrm{p}$ $=0.022)$ and creatinine $(0.8 \mathrm{mg} / \mathrm{dl}$ vs 0.7 $\mathrm{mg} / \mathrm{dl}, \mathrm{p}<0.001$ ) in phase I. No significant differences in BUN or creatinine levels were noted at day 28. There were no significant differences in serum bilirubin, AST, ALP and GGT between the two groups at day 1, day 7 , or day 28. There was no increase in the average weight gain noted at 28 days in phase II (15 g/k/day vs $13 \mathrm{~g} / \mathrm{k} /$ day, $\mathrm{p}=$ 0.282 ). 
Table 1. Demographics characteristics.*

\begin{tabular}{|c|c|c|c|}
\hline & Phase I & Phase II & \\
\hline Total number & 181 & 181 & \\
\hline Gestational age in weeks (S.D.) & $29(2)$ & $29(2)$ & \\
\hline Birth weight in kg (S.D.) & $1.152(0.252)$ & $1.156(0.247)$ & \\
\hline Male (percent) & $87(48 \%)$ & $105(58 \%)$ & $\begin{array}{c}X^{2}(1)=3.593 \\
p=0.058\end{array}$ \\
\hline Multiple gestation (percent) & $10(6 \%)$ & $19(11 \%)$ & $\begin{array}{c}\mathrm{X}^{2}(1)=3.036 \\
\mathrm{p}=0.081\end{array}$ \\
\hline \multicolumn{4}{|c|}{ Ethnicity } \\
\hline White (percent) & $133(73 \%)$ & $142(78 \%)$ & \multirow{5}{*}{$\begin{array}{c}X^{2}(3)=2.139 \\
p=0.544\end{array}$} \\
\hline Black (percent) & $19(10 \%)$ & $16(9 \%)$ & \\
\hline Hispanic (percent) & $23(13 \%)$ & $16(9 \%)$ & \\
\hline Other (percent) & $5(3 \%)$ & $7(4 \%)$ & \\
\hline Missing (percent) & $1(1 \%)$ & $0(0.0 \%)$ & \\
\hline
\end{tabular}

$* \mathrm{X}^{2}=$ chi square test

Table 2. Differences between Phase I and Phase II.*

\begin{tabular}{|c|c|c|c|}
\hline & Phase I & Phase II & \\
\hline $\begin{array}{l}\text { Total protein dose (S.D.) } \\
\text { 1st } 7 \text { days in g/kg }\end{array}$ & $12.8(6.7)$ & $16(7.5)$ & $\begin{array}{c}\mathrm{w}=-4.686 \\
\mathrm{p}<0.001\end{array}$ \\
\hline $\begin{array}{l}\text { Total protein dose (S.D.) } \\
1 \text { st } 28 \text { days in } \mathrm{g} / \mathrm{kg}\end{array}$ & $84(30)$ & $85(32.6)$ & $\begin{aligned} \mathrm{w} & =0.086 \\
\mathrm{p} & =0.932\end{aligned}$ \\
\hline TPN day count (S.D.) & $18(7)$ & $16(7)$ & $\begin{array}{c}\mathrm{w}=-3.347 \\
\mathrm{p}=0.001\end{array}$ \\
\hline $\begin{array}{l}\text { Enteral feed day count } \\
\text { (S.D.) }\end{array}$ & $21(5.3)$ & $20(5.5)$ & $\begin{array}{c}\mathrm{w}=-0.788 \\
\mathrm{p}=0.431\end{array}$ \\
\hline $\begin{array}{l}\text { Weight gain in g/ day } \\
\text { (S.D.) }\end{array}$ & $13(6)$ & $15(10)$ & $\begin{aligned} \mathrm{w} & =1.076 \\
\mathrm{p} & =0.282\end{aligned}$ \\
\hline
\end{tabular}

$*_{\mathrm{w}}=$ Wilcoxon signed rank test

\section{Discussion}

The change in protocol was associated with an increase in the total dose of protein administered by day 7 and a more rapid transition to enteral feedings resulting in a shorter duration of TPN use. Enteral intake reduces the protein intake given that Neosure (22 Kcal/ oz) at $150 \mathrm{ml} / \mathrm{k} /$ day yields $3 \mathrm{~g} / \mathrm{k} /$ day of protein. Hence, improved enteral tolerance resulted in an earlier transition to enteral feeds and resulted in a lower total dose of protein at day 28 .
As with a previous study, no hepatic dysfunction was noted. ${ }^{7}$ No detrimental effects in the form of an increase in the incidence of feeding intolerance, bowel perforation, or renal dysfunction were noted. Contrary to our hypothesis, no clear advantage in terms of absolute weight gain was noted. This was consistent with one previous study. ${ }^{9}$ In our study, infants were not followed to dismissal given the high transfer rate out of the practice to other sites 
Table 3. Adverse effects and laboratory results.*

\begin{tabular}{|c|c|c|c|}
\hline & Phase I & Phase II & \\
\hline $\begin{array}{l}\text { Feeding Intolerance } \\
\text { (percent) }\end{array}$ & $13(7 \%)$ & $20(11 \%)$ & $\begin{array}{c}X^{2}(1)=1.634 \\
p=0.201\end{array}$ \\
\hline $\begin{array}{l}\text { Bowel perforation } \\
\text { (percent) }\end{array}$ & $2(1 \%)$ & $0(0 \%)$ & $\begin{array}{c}X^{2}(1)=2.011 \\
p=0.499\end{array}$ \\
\hline \multicolumn{4}{|c|}{ Day 1 lab results } \\
\hline BUN mg/dl (S.D.) & $14(7)$ & $18(8)$ & $\mathrm{w}=5.181, \mathrm{p}<0.001$ \\
\hline Creatinine $\mathrm{mg} / \mathrm{dl}$ (S.D.) & $0.8(0.3)$ & $0.8(0.3)$ & $\mathrm{w}=-1.753, \mathrm{p}=0.080$ \\
\hline Bilirubin mg/dl (S.D.) & $0.2(0.2)$ & $0.2(0.2)$ & $\mathrm{w}=-0.222, \mathrm{p}=0.824$ \\
\hline AST U/L (S.D.) & $21(23)$ & $22(28)$ & $\mathrm{w}=0.229, \mathrm{p}=0.819$ \\
\hline ALP U/L (S.D.) & $118(124)$ & $134(135)$ & $\mathrm{w}=1.195, \mathrm{p}=0.232$ \\
\hline GGT U/L (S.D.) & $65(92)$ & $62(76)$ & $\mathrm{w}=-0.011, \mathrm{p}=0.992$ \\
\hline \multicolumn{4}{|c|}{ Day 7 lab results } \\
\hline BUN mg/dl (S.D.) & $19(10)$ & $18(12)$ & $\mathrm{w}=-2.283, \mathrm{p}=0.022$ \\
\hline Creatinine mg/dl (S.D.) & $0.8(0.3)$ & $0.7(0.3)$ & $\mathrm{w}=-4.023, \mathrm{p}<0.001$ \\
\hline Bilirubin mg/dl (S.D.) & $0.2(0.2)$ & $0.3(0.2)$ & $\mathrm{w}=0.208, \mathrm{p}=0.835$ \\
\hline AST U/L (S.D.) & $17(15)$ & $16(14)$ & $w=-0.646, p=0.518$ \\
\hline ALP U/L (S.D.) & $213(197)$ & $210(188)$ & $\mathrm{w}=0.009, \mathrm{p}=0.993$ \\
\hline GGT U/L (S.D.) & $59(94)$ & $45(52)$ & $w=-0.603, p=0.564$ \\
\hline \multicolumn{4}{|c|}{ Day 28 lab results } \\
\hline BUN mg/dl (S.D.) & $3(5)$ & $3(4)$ & $\mathrm{w}=0.604, \mathrm{p}=0.546$ \\
\hline Creatinine $\mathrm{mg} / \mathrm{dl}$ (S.D.) & $0.2(0.3)$ & $0.2(0.2)$ & $w=-0.940, p=0.347$ \\
\hline Bilirubin mg/dl (S.D.) & $0.2(1)$ & $0.2(0.6)$ & $\mathrm{w}=0.880, \mathrm{p}=0.379$ \\
\hline AST U/L (S.D.) & $9(16)$ & $10(18)$ & $\mathrm{w}=0.055, \mathrm{p}=0.956$ \\
\hline ALP U/L (S.D.) & $172(264)$ & $171(241)$ & $\mathrm{w}=0.100, \mathrm{p}=0.920$ \\
\hline GGT U/L (S.D.) & $26(55)$ & $33(64)$ & $\mathrm{w}=1.674, \mathrm{p}=0.094$ \\
\hline
\end{tabular}

${ }^{*} \mathrm{~W}=$ Wilcoxon signed rank test, $\mathrm{X}^{2}=$ Chi square test

and other care providers.

A limitation of this study was its retrospective design and the inherent possibility of failure to capture elements of care which might be recognized as influential. In both phases, the total dose of amino acids administered at times exceeded the maximum amount dictated by the protocol. The total dose was left to the individual clinician's discretion. Another such clinical decision was the timing of transition from intravenous to enteral nutrition. These factors might have contributed to some variability in the data.

\section{Conclusion}

Given that no unfavorable outcomes were demonstrated with the increased amino acid regimen, VLBW infants may be able to tolerate, and benefit from, even higher doses of amino acids in the first month after birth. 


\section{References}

${ }^{1}$ Clark RH, Wagner CL, Merritt RJ, et al. Nutrition in the neonatal intensive care unit: How do we reduce the incidence of extrauterine growth restriction? J Perinatol 2003; 23(4): 337-344. PMID: 12774145.

2 Ehrenkranz, Dusick AM, Vohr BR, Wright LL, Wrage LA, Poole WK. Growth in the neonatal intensive care unit influences neurodevelopmental and growth outcomes of extremely low birth weight infants. Pediatrics 2006; 117:1253-1261. PMID: 16585322.

${ }^{3}$ Poindexter BB, Langer JC, Dusick AM, Ehrenkranz RA, National Institute of Child Health and Human Development Neonatal Research Network. Early provision of parenteral amino acids in extremely low birth weight infants: Relation to growth and neurodevelopmental outcome. J Pediatr 2006; 148:300-305. PMID: 16615955.

4 Ehrenkranz RA, Younes N, Lemons JA, et al. Longitudinal growth of hospitalized very low birth weight infants. Pediatrics 1999; 104(2, Pt 1):280-289. PMID: 10429008.

5 Ziegler EE. Protein in premature feeding. Nutrition 1994; 10(1):69-71. PMID: 8199428.

${ }^{6}$ Valentine CJ, Fernandez S, Rogers LK, et al. Early amino-acid administration improves preterm infant weight. $\mathbf{J}$ Perinatol 2009; 29(6):428-432. PMID: 19444236.
7 Kotsopoulos K, Benadiba-Torch A, Cuddy A, Shah PS. Safety and efficacy of early amino acids in preterm $<28$ weeks gestation: Prospective observational comparison. J Perinatol 2006; 26(12):749754. PMID: 17024139.

8 Porcelli Jr PJ, Sisk PM. Increased parenteral amino acid administration to extremely low birth weight infants during early postnatal life. J Pediatr Gastroenterol Nutr 2002; 34(2):174-179. PMID: 11840036.

9 Clark RH, Chace DH, Spitzer AR, Pediatrix Amino Acid Study Group. Effects of two different doses of amino acid supplementation on growth and blood amino acid levels in premature neonates admitted to the neonatal intensive care unit: A randomized, controlled trial. Pediatrics 2007; 120(6);1286-1296. PMID: 18055678.

${ }^{10}$ Thureen PJ, Melara D, Fennessey PV, Hay WW Jr. Effect of low versus high intravenous amino acid intake on very low birth weight infants in the early neonatal period. Pediatr Res 2003; 53(1):24-32. PMID: 12508078.

${ }^{11}$ Catzeflis C, Schutz Y, Micheli JL, Welsch C, Arnaud MJ, Jéquier E. Whole body protein synthesis and energy expenditure in very low birth weight infants. Pediatr Res 1985; 19(7):679-687. PMID: 4022675.

Keywords: parenteral nutrition, amino acids, very low birth weight infants 